\title{
Análise socioeconômica e esforço de pesca na captura do caranguejo-uçá - Ucides cordatus (Crustacea: Ucididae) - na Reserva Extrativista Maracanã - costa amazônica do Brasil Socio-economic analysis and the mangrove crab - Ucides cordatus (Crustacea: Ucididae) - fishing effort in the Maracanã Extractive Reserve - Amazon coast of Brazil
}

\author{
Ádria de Carvalho Freitas', Ivan Furtado-júnior', \\ Márcia Cristina da Silva Tavares", Elielma Ribeiro Borcem"III \\ Universidade Federal Rural da Amazônia. Belém, Pará, Brasil \\ "Universidade Federal do Pará. Belém, Pará, Brasil \\ "'IMinistério da Pesca e Aquicultura. Brasília, Distrito Federal, Brasil
}

\begin{abstract}
Resumo: Este artigo avalia social e economicamente a captura de caranguejo-uçá em Maracanã-PA. As informações foram adquiridas através de entrevistas semiestruturadas, conversas informais e acompanhamento da pescaria do caranguejo. Dos dados coletados foi feita uma análise estatística descritiva, utilizando a média como medida da tendência central e o coeficiente de variação foi empregado como medida de heterogeneidade dentro de cada variável amostrada. A renda total anual e o esforço de pesca dos caranguejeiros profissionais foram calculados. Cerca de 20\% dos 5.000 usuários da Reserva Extrativista Maracanã trabalha com a captura do caranguejo. A CPUE variou de 20 a 400 caranguejos por homem-dia, com média de 92,2 ( $\pm 39,2)$. Todos os pescadores entrevistados utilizam como técnica de pesca o método tradicional do braço ("braceamento") combinado com o uso do gancho, empregado como instrumento prolongador do braço na captura. O esforço de pesca aumentou continuamente no período de 1995 a 2007, correspondendo a 68,93\%, passando de 42.172 para 71.240 homens-dia.
\end{abstract}

Palavras-chave: Captura de caranguejo. Esforço de pesca. Manguezal. Renda. Pesca artesanal. RESEX.

Abstract: This article presents a social and economic evaluation of land crab fishing in Maracanã-PA. Information was obtained through semi-structured interviews, informal conversations, and monitoring of crab fishing. The collected data formed the basis for a descriptive statistical analysis, using the mean as a measure of the central tendency and the variation coefficient as a measure of heterogeneity within each sampled variable. The total annual income and fishing effort of the professional crab catchers were calculated. About 20\% of the 5,000 users of the Maracanã Extractive Reserve work in the crab catch. The capture rates per effort unit ranged from 20 to 400 crabs per man-day, averaging $92.2( \pm 39.2)$. All interviewed fishermen used the traditional "arm method" (braceamento) fishing technique, combined with the use of hooks as an extension tool of the arm. The fishing effort increased steadily from 1995 to 2007 , corresponding to $68.93 \%$, from 42,172 to 71,240 man-days.

Keywords: Crab catching. Fishing effort. Mangrove. Income. Small-scale fishing. Extractive reserve.

FREITAS, Ádria de Carvalho; FURTADO-JÚNIOR, Ivan; TAVARES, Márcia Cristina da Silva; BORCEM, Elielma Ribeiro. Análise socioeconômica e esforço de pesca na captura do caranguejo-uçá - Ucides cordatus (Crustacea: Ucididae) - na Reserva Extrativista Maracanã - Costa Amazônica do Brasil. Boletim do Museu Paraense Emílio Goeldi. Ciências Humanas, v. 10, n. 3, p. 711-722, set./dez. 2015. DOI: http://dx.doi. org/10.1590/1981-81222015000300012.

Autor para correspondência: Ivan Furtado-Júnior. Endereço residencial: Quadra 204, Lote 09, Bloco A, Apto. 104, Sul - Águas Claras. Brasília, DF, Brasil. CEP 71939 540. E-mail: juniorivan@hotmail.com.

Recebido em 28/02/2014

Aprovado em 30/10/2015

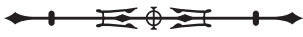




\section{INTRODUÇÃO}

O manguezal é um ecossistema de transição entre o ambiente marinho e o terrestre (Vegas-Vélez, 1978), que de acordo com Spalding, Kainuma e Collins (2010) possui área total estimada em cerca de $152.000 \mathrm{~km}^{2}$. O litoral brasileiro possui o equivalente a 8,5\% deste total, 13.000 $\mathrm{km}^{2}$, lhe conferindo a segunda maior extensão de áreas de manguezal a nível mundial, ficando atrás apenas da Indonésia, com uma área de 30.000 km² (21\%).

$\mathrm{Na}$ costa brasileira, os manguezais ocorrem desde o Amapá até Santa Catarina, margeando estuários, lagunas e enseadas costeiras (Lacerda, 2003). Segundo o Programa das Nações Unidas para o Desenvolvimento (2008) estima-se que 56\% das áreas de manguezais do Brasil encontrem-se dentro de unidades de conservação, sendo quase $80 \%$ na categoria de Uso Sustentável e os 20\% restantes em Proteção Integral. Em 2014, após a criação de mais três reservas extrativistas no estado do Pará - Mocapajuba (Brasil, 2014a), Mestre Lucindo (Brasil, 2014b), Cuinarana (Brasil, 2014c) - e ampliação da Reserva Extrativista Marinha Araí-Peroba (Brasil, 2014d), a área em unidades de conservação, na região, aumentou em 51\%, chegando a 322 mil hectares (Instituto Chico Mendes de Conservação da Biodiversidade, 2014).

No Pará, as áreas de manguezais formam uma faixa quase contínua de $300 \mathrm{~km}$ de extensão, com uma área total de $2.176,78 \mathrm{~km}^{2}$ (Souza-Filho, 2005). O caranguejouçá Ucides cordatus (Linnaeus, 1763) é um importante elemento da fauna em toda sua área de ocorrência nas regiões de mangue do Brasil, assumindo características de recurso pesqueiro de elevado valor (Ivo et al, 2000).

As Reservas Extrativistas (RESEX) são resultado de uma luta histórica pela posse da terra pelos seringueiros amazônicos com o objetivo de utilizar recursos florestais de maneira sustentável, buscando promover justiça social e proteção ambiental (Diegues, 2001).

Foram criadas a partir de 1990 como espaços territoriais destinados a assegurar o uso sustentável dos recursos naturais e proteger o meio de vida e a cultura das populações tradicionais das florestas, segundo o Conselho Nacional dos Seringueiros (Conselho Nacional de Seringueiros, 1992).

A Reserva Extrativista Maracanã - RESEX Maracanã foi criada pelo decreto de 13 de dezembro de 2002, com os objetivos de assegurar o uso sustentável e a conservação dos recursos naturais renováveis, protegendo os meios de vida e a cultura da população extrativista local (Brasil, 2002).

Maracanã é um dos municípios paraenses em que o caranguejo-uçá destaca-se na produção de pescado, segundo Furtado-Júnior, Tavares e Brito (2006), somente no período de 1997 a 2003 (sete anos) a média de desembarques oriundos de Maracanã totalizou 694,5 toneladas de caranguejo. Apesar de tais dados indicarem uma extração de quase 700 toneladas/ano, eles não demonstram a realidade desse município paraense, pois tratam apenas da produção desembarcada, sem contabilização das produções transportadas por bicicletas, carroças e até mesmo a pé, sendo capturadas pelas mais variadas artes.

Os estudos direcionados à avaliação das atividades econômicas costeiras contribuem com o índice de conhecimento regional e, ao mesmo tempo, nos capacita a desenvolver uma ideia crítica em relação ao sistema econômico e de desenvolvimento das comunidades envolvidas nas atividades ligadas à extração e comercialização dos recursos naturais em ambientes marinhos e costeiros (Terceiro; Santos; Correia, 2013).

Assim, o presente estudo faz-se necessário para a estimativa do real esforço empregado na pesca do caranguejo-uçá em Maracanã, bem como para a caracterização dos atores sociais envolvidos nesse sistema, vista a importância do mesmo para o sustento de grande parte das famílias da Reserva Extrativista Maracanã e do município na produção desta espécie de crustáceo no estado do Pará.

\section{MATERIAL E MÉTODOS}

A RESEX Maracanã compreende uma área de mais de 30 mil hectares, localizada no município de Maracanã (Figura 1), 
tendo vegetação constituída por mata de terra firme, florestas secundárias, vegetação de várzea e manguezais. A RESEX Maracanã é composta por 75 comunidades de ribeirinhos banhadas pelos rios Marapanim, Cuinarana, Maracanã, Caripi e a baía de Maracanã. Nesta reserva habitam 1500 famílias, totalizando mais de cinco mil usuários que ali vivem e sobrevivem dos recursos naturais que extraem, como peixes e crustáceos oriundos principalmente dos manguezais (Santos, 2008).

Estes cinco mil usuários são representados pela Associação dos Usuários da Reserva Extrativista Maracanã (AUREMAR), com sede no próprio município. Além disso, a reserva conta com um Conselho Deliberativo, e de uma Comissão de Proteção da Reserva, formada por representantes dos usuários, indicados por suas comunidades e aprovados pela AUREMAR, que são responsáveis pela execução do Plano de Utilização (Santos, 2008).

A coleta de dados apresentadas no presente estudo ocorreu de 10/07/2008 a 04/08/2008, sendo as informações adquiridas pela aplicação de entrevistas semiestruturadas, conversas informais e acompanhamento da pescaria (captura) do caranguejo.

As entrevistas foram realizadas mais precisamente na cidade e algumas localidades do município, com pescadores que tinham experiência na pesca e/ou eram reconhecidos na comunidade como detentores de conhecimento referente à extração ou captura de recursos pesqueiros. As entrevistas semiestruturadas permitiram a coleta de informações básicas e iguais sobre a pesca, de forma relativamente rápida e menos dispendiosa.

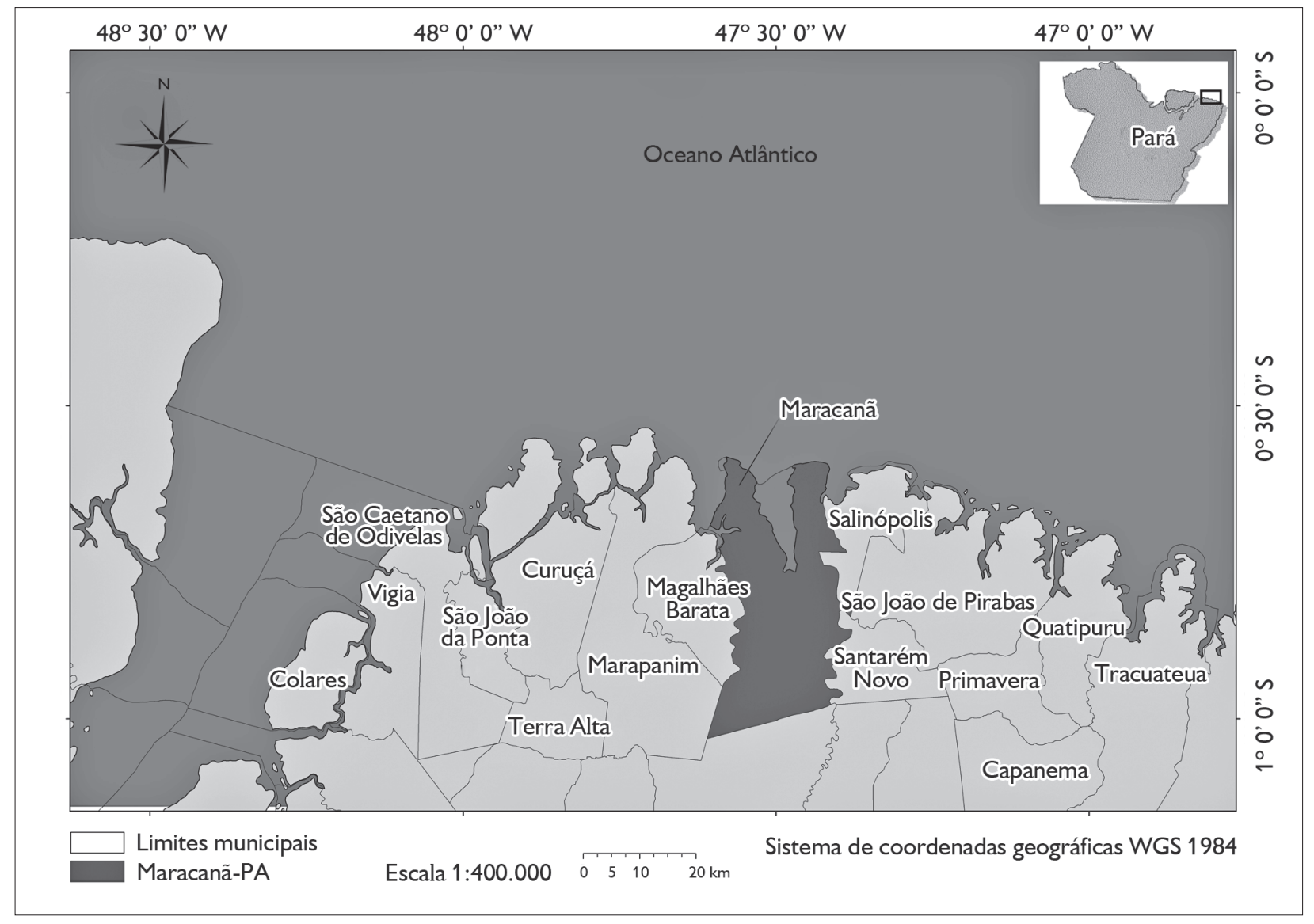

Figura 1. Localização do município de Maracanã, no estado do Pará, Brasil.

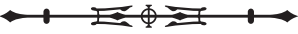


Dos dados coletados foi feita uma análise com base nos resultados da estatística descritiva quando foram calculados os seguintes itens: valores mínimos e máximo; amplitude total; média aritmética; variância; desvio padrão; erro padrão e coeficiente de variação. Dessa forma a média foi utilizada como medida da tendência central e o coeficiente de variação (CV) foi empregado como medida de heterogeneidade dentro de cada variável amostrada.

A renda total anual foi calculada, para os caranguejeiros que comercializam a captura em unidades, multiplicandose o valor unitário de primeira comercialização (preço de venda direta ao consumidor ou para o atravessador) pelo número de dias de trabalho por semana e pelo número de semanas trabalhadas por ano. A renda mensal anual foi calculada dividindo-se a renda total anual pelo número de meses do ano.

O esforço de pesca dos caranguejeiros profissionais foi calculado pela multiplicação do número de dias de trabalho por semana pelo número de semanas trabalhadas por ano, utilizando-se como unidade de esforço de pesca "homem-dia". O esforço de pesca total anual foi calculado pelo somatório dos esforços de pesca de cada profissional no período de 1995 a 2007.

\section{RESULTADOS}

Um total de 316 pescadores foi entrevistado no período de estudo, sendo todos do sexo masculino. A idade dos pescadores variou de 17 a 90 anos com média de $40,20( \pm 11,70)$ anos. O coeficiente de variação deste parâmetro foi $29,1 \%$, demonstrando homogeneidade quanto a idade média (Tabela 1).

Houve elevada amplitude quanto ao tempo de trabalho na profissão (73 anos), entre 2 e 75 anos, com média de 19,1( $\pm 11,9)$ anos e um coeficiente de variação de $62,8 \%$, evidenciando uma grande heterogeneidade neste parâmetro (Tabela 1). A renda média mensal declarada apresentou uma grande discrepância para menos quando compara com a renda média mensal, calculada com base no número de dias trabalhados por semana e a captura por unidade de esforço (Tabela 1). Com relação à moradia, existe indicação de que 99,7\% dos caranguejeiros possuíam habitação própria, com apenas um tendo declarado morar em habitação emprestada.

O número de dias de pesca durante a semana foi intenso para todos os pescadores amostrados (4,3 \pm dias) semana), com pouca variabilidade entre eles ( $C V=22,5 \%)$, com o valor unitário de primeira comercialização do caranguejo variando entre $R \$ 0,20$ à $R \$ 0,50 /$ unidade,

Tabela 1. Estatística descritiva das amostras $(\mathrm{N})$ em relação à idade, tempo de trabalho na profissão, renda média mensal declarada e calculada, maior e menor renda mensal declarada dos tiradores de caranguejo da Reserva Extrativista Maracanã (RESEX Maracanã).

\begin{tabular}{c|c|c|c|c|c|c}
\hline $\begin{array}{c}\text { Sumário } \\
\text { Estatístico }\end{array}$ & $\begin{array}{c}\text { Idade } \\
\text { (anos) }\end{array}$ & $\begin{array}{c}\text { Tempo de } \\
\text { trabalho na } \\
\text { rrofissão (anos) }\end{array}$ & $\begin{array}{c}\text { Renda média } \\
\text { mensal } \\
\text { declarada (R\$) }\end{array}$ & $\begin{array}{c}\text { Renda média } \\
\text { mensal } \\
\text { calculada (R\$) }\end{array}$ & $\begin{array}{c}\text { Maior renda } \\
\text { mensal } \\
\text { declarada (R\$) }\end{array}$ & $\begin{array}{c}\text { Menor renda } \\
\text { mensal } \\
\text { declarada (R\$) }\end{array}$ \\
\hline N & 316 & 316 & 316 & 49 & 316 & 316 \\
\hline Mínimo & 17 & 2 & 50,00 & 123,10 & 80,00 & 15 \\
\hline Máximo & 90 & 75 & 600,00 & $2.533,33$ & $1.500,00$ & 500 \\
\hline Amplitude Total & 73 & 73 & 550,00 & $2.410,23$ & $1.420,00$ & 485 \\
\hline Erro Padrão & 0,66 & 0,67 & 6,09 & 58,23 & 7,34 & 3,84 \\
\hline Média Aritmética & 40,20 & 19,11 & 183,73 & 608,06 & 326,88 & 104,63 \\
\hline Desvio Padrão & 11,70 & 11,99 & 108,27 & 407,64 & 130,53 & 68,33 \\
\hline $\begin{array}{c}\text { Coeficiente de } \\
\text { Variação }\end{array}$ & $29,09 \%$ & $62,77 \%$ & $58,93 \%$ & $67,04 \%$ & $39,93 \%$ & $65,31 \%$ \\
\hline
\end{tabular}

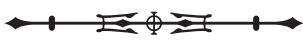


dependendo do comprador (Tabela 2). No caso da captura por unidade de esforço (CPUE), verificou-se elevada variabilidade (CV>42\%), variando de 20 a 400 caranguejos/homem/dia, com média de 92,2ะ39,29 caranguejos/homem/dia.

Do total de pescadores entrevistados (316) verificouse que $100 \%$ deles utilizam como técnica de pesca o método tradicional do braço combinado com o gancho.

A Figura 2 resume os dados de esforço de pesca dos caranguejeiros profissionais, que vem aumentando continuamente desde 1995 até 2007, aproximadamente na faixa de $68,9 \%$, com maior aumento relativo de 1998 para 1999 (22,9\%). No período de 2005 a 2007 é possível verificar uma homogeneidade entre os valores, que parecem chegar a um valor assintótico.

\section{DISCUSSÃO}

A ausência de entrevistados do sexo feminino na pesca do caranguejo-uçá na RESEX Maracanã evidenciou a divisão de trabalho entre os membros de sexos diferentes nas famílias dos pescadores. Assim, enquanto os homens dedicam-se a captura dos caranguejos "tiração", as mulheres dedicam-se ao trabalho de "catação", além de executarem as demais atividades domésticas. Tal fato foi

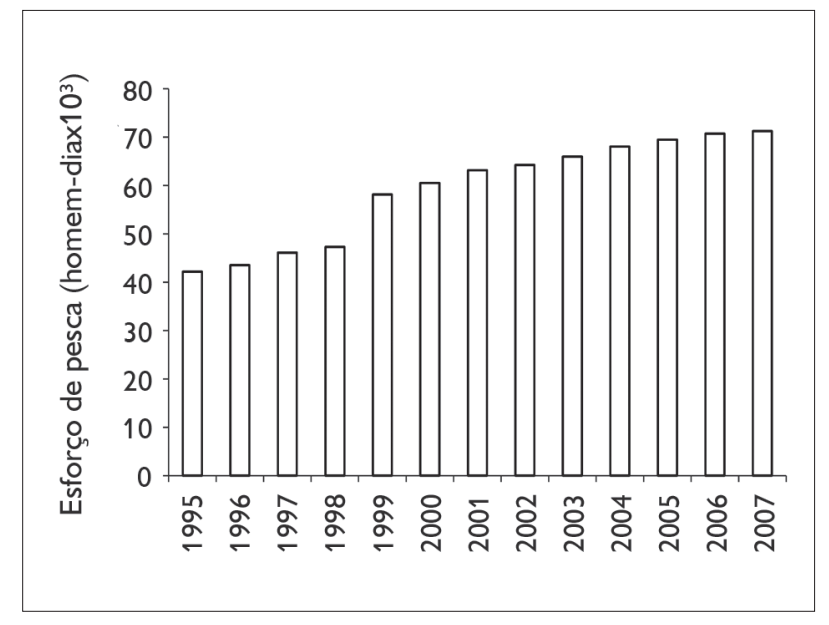

Figura 2. Evolução do esforço de pesca, na captura do caranguejouçá (Ucides cordatus), durante o período de 1995 a 2007 na RESEX Maracanã - estado do Pará, Brasil.

anteriormente mencionado por Machado (2007) para a Vila de Guarajubal, comunidade tradicionalmente voltada à captura de caranguejo, no município de Marapanim (PA), corroborando Borcem et al (2011). No entanto, realidades como a da Vila do Sorriso em São Caetano de Odivelas (PA), diferem da divisão sexual de trabalho observada, sendo o número de mulheres atuantes na pesca do caranguejo próximo ao de homens (Moraes; Almeida, 2012), chegando a ser superior ao número de homens

Tabela 2. Estatística descritiva das amostras (N) em relação à frequência de pesca (dias/semana), valor unitário de primeira comercialização $(R \$)$, captura por unidade de esforço (CPUE) e renda total anual (R\$) na Reserva Extrativista Maracanã (RESEX Maracanã).

\begin{tabular}{c|c|c|c|c}
\hline $\begin{array}{c}\text { Sumário } \\
\text { Estat́stico }\end{array}$ & $\begin{array}{c}\text { Frequência de } \\
\text { Pesca (dias/semana) }\end{array}$ & $\begin{array}{c}\text { Valor unitário de primeira } \\
\text { comercialização* (R\$) }\end{array}$ & $\begin{array}{c}\text { Captura por unidade } \\
\text { de esforço (CPUE) }\end{array}$ & $\begin{array}{c}\text { Renda total anual } \\
\text { (R\$) }\end{array}$ \\
\hline $\mathrm{N}$ & 316 & 49 & 316 & 49 \\
\hline Mínimo & 2 & 0,20 & 20 & $1.477,14$ \\
\hline Máximo & 7 & 0,50 & 400 & $30.400,00$ \\
\hline Amplitude Total & 5 & 0,30 & 380 & $28.922,86$ \\
\hline Erro Padrão & 0,05 & 0,01 & 2,21 & 698,81 \\
\hline Média Aritmética & 4,34 & 0,31 & 92,22 & $7.296,73$ \\
\hline Desvio Padrão & 0,97 & 0,09 & 39,29 & $4.891,70$ \\
\hline $\begin{array}{c}\text { Coeficiente de } \\
\text { Variação }\end{array}$ & $22,5 \%$ & $29,5 \%$ & $42,61 \%$ & $67,04 \%$ \\
\hline
\end{tabular}

*Primeira comercialização é aquela entre o produtor e o primeiro comprador de caranguejo.

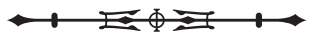


nas comunidades de Atafona e Grajaú no norte do Rio de Janeiro (Côrtes; Zappes; Beneditto, 2014).

A "catação" corresponde ao beneficiamento dos animais capturados para a extração da carne (denominada "massa"), que é um produto altamente comercializado em diversos municípios do estado e com maior demanda que o caranguejo inteiro. Por este motivo, além de auxiliarem no trabalho dos maridos, também é comum que as "catadoras" maracanaenses sejam contratadas por outros "tiradores" ou comerciantes para a produção de "massa", lhes conferindo grande importância na cadeia de comercialização do caranguejo-uçá neste município.

Cardoso (2000) e Machado (2007) concluíram que a pesca artesanal desenvolvida nos manguezais da Vila de Guarajubal, assim como em Maracanã, era direcionada à captura/beneficiamento do caranguejo-uçá, contando decisivamente com o trabalho das mulheres pela maior demanda do produto oriunda de centros urbanos próximos. A carne do caranguejo já "catada" passou a ser produzida para comercialização, não estando mais voltada ao consumo pelas próprias famílias dos tiradores e catadoras. Ressaltaram, ainda, que o trabalho das catadoras, embora não fosse enfatizado publicamente, possibilitava a manifestação dessas mulheres sobre problemas comunitários, como os educacionais, decorrentes da ausência de saneamento básico, ou de outras infraestruturas necessárias à sua vila. Esse cenário também foi observado por Vieira et al (2013) em comunidades do município de Bragança, principalmente na Vila do Treme, onde a "massa" do caranguejo era o principal produto comercializado.

De acordo com Maneschy (2000), muitas mulheres que se integram ao setor pesqueiro geralmente desenvolvem outras atividades em paralelo muitas vezes figurando como auxiliares dos maridos e não como unidades produtivas. Este autor enfatiza, ainda, que os trabalhos desenvolvidos pelas mulheres são realizados ordinariamente em terra, seja por consertos feitos às redes de pesca como o beneficiamento do pescado.
A alta homogeneidade em relação à idade média (40,2 anos) dos catadores é indício de evasão da atividade pesqueira pelos jovens, que seguem outras profissões, sendo raros os casos de continuidade nesse trabalho dos manguezais, o que ocorre por carência de opção por outras atividades. Outros trabalhos que abordam a idade destes pescadores na mesma mesorregião de Maracanã são similares aos encontrados na atual pesquisa, como o de Mello et al (2006), em seu estudo na vila de Camará, no município de Marapanim, onde a idade dos tiradores oscilava entre 22 e 57 anos (média de 35 anos) e 46\% dos homens estavam na faixa entre 31 a 40 anos. Neste município Borcem et al (2011) avaliaram quatro vilas, sendo a pesca de caranguejo bastante significativa em Guarajubal, onde a média de idade dos pescadores foi de 42 anos, com 45\% desses trabalhadores entre 21 a 40 anos, não sendo evidenciada diferença significativa entre as médias de idade quando essas quatro vilas foram confrontadas estatisticamente (ANOVA com Tukey, $p<0,05$ ). Em outras regiões do litoral brasileiro os resultados foram similares, como no Sudeste, onde Fiscarelli e Pinheiro (2002) registraram idades para os catadores de caranguejo variando de 16 a 58 anos; e no Nordeste, onde a idade variou de 23 a 65 anos, com média de 43 anos, sendo 32,5\% entre 51 e 60 anos (Vasconcelos, 2008).

Segundo Borcem et al (2011) o maior número de pescadores em idade adulta se justifica pelo direcionamento dos mais jovens para o comércio local ou mesmo outras profissões, como pedreiros e marceneiros, na maioria das vezes consideradas de maior validade do que a atividade pesqueira. Além disso, o maior incentivo ao estudo pelos pais geralmente norteia esses jovens para outras realidades, afastando-se do ambiente pesqueiro.

Os resultados registrados no presente estudo diferenciam Maracanã por uma maior abrangência etária dos catadores, onde figuram as menores e maiores idades quando confrontadas a outras localidades do norte e nordeste brasileiro. Outro aspecto foi o elevado tempo médio de atuação na atividade (19,1 anos), o 
que ratifica a falta de alternativas de geração de renda para esses trabalhadores do setor pesqueiro, embora a predominância de adultos na atividade indique outras oportunidades de trabalho aos mais jovens.

Houve discrepância entre a renda média mensal declarada e calculada, possivelmente pela ausência de contabilização diária dos rendimentos pelos tiradores, já que grande parte comercializa sua produção diariamente, dificultando o cálculo de valor/mês. Gastos diários com o "rancho" (p. ex., alimentação, conserto/confecção de apetrechos de pesca, aquisição do diesel e compra do tabaco para afugentar os insetos durante a captura), compras domésticas e pagamentos de pequenas dívidas em tabernas, dificulta ao tirador uma noção de ganhos com a atividade de pesca. Por outro lado, as maiores e menores rendas, são memorizadas com maior facilidade, por serem eventos marcantes, tanto pelas alegrias proporcionadas como pelas dificuldades enfrentadas, respectivamente. Em Maracanã a diferença entre as duas rendas médias mensais, declarada ( $R \$ 183,73$ ) e calculada ( $R \$ 608,06$ ) foi quase $70 \%$. No município de São João de Pirabas (PA), Cordovil et al (2014) observaram que os tiradores também possuem dificuldade em contabilizar seus rendimentos, sendo que o valor da renda média declarada $(R \$ 396,46)$ caia quase pela metade quando comparado a renda média calculada $(R \$ 799,29)$.

Quando comparada a renda média declarada pelos tiradores de Maracanã (R\$183,73) ao salário mínimo da época (Salário Mínimo - SM no ano de $2008=$ R\$ 415,00), essa se mostrou bem menor. Em outras localidades, por exemplo, Iguapé (SP) foi de R\$377,50 (SM no ano de 2000 $=\mathrm{R} \$ 151,00$ (Fiscarelli; Pinheiro, 2002); Carnaubeiras (MA) entre $R \$ 250,00$ e $R \$ 500,00$ (SM em $2011=R \$ 545,00$ ) (Cavalcante et al, 2011); Delta do Parnaíba R\$900,00 e llha de São Luís (MA) R\$ 600,00 (SM no ano de $2013=R \$$ 678,00) (Terceiro; Santos; Correia, 2013), essa diferença varia bastante. No entanto, demostram, em sua maioria, que os tiradores de caranguejo enquadram-se entre os $10 \%$ mais pobres da população. Outros estudos realizados por Alves e Nishida (2003) e Barbosa et al (2008) indicam que a renda auferida é inferior a um salário mínimo, o que levou Nordi (1992) a afirmar que os catadores de caranguejo figuram entre os pescadores com menor poder aquisitivo. Tais observações podem estar atreladas às diferentes formas de comercialização do produto, já que depois de capturados são vendidos de duas formas (vivos ou "catados"), impossibilitando agregação de valor ao produto, o que é incorporado somente mais ao final da cadeia de comercialização. Por ser um produto altamente perecível, com falta de tecnologia associada ao seu manejo pelas comunidades pesqueiras, não possibilita alternativas ao catador, que requer vender com maior rapidez toda a sua produção.

O coeficiente de variação do preço de primeira comercialização do caranguejo-uçá foi muito reduzido (29,5\%), sugerindo uma variável pouco heterogênea na comercialização. Este parâmetro gerou valores relativamente constantes ao longo do tempo, sendo controlados por poucos atravessadores que trabalhavam em uma organização semelhante à de um cartel. Tal fato foi verificado no Delta do Parnaíba por Assad et al, (2012), que informa sobre a comercialização do caranguejo-uçá majoritariamente vivo, o que foi efetuado nos locais de desembarque aos atravessadores (primeira transação comercial), bem como ao consumidor final, evidenciando valores variando de $\mathrm{R} \$$ 0,80 a $R \$ 1,00 /$ corda de caranguejos ( $R \$ 0,20$ a $R \$ 0,25$ / unidade), enquanto a carne de caranguejo congelada era vendida entre $R \$ 11,00$ e $R \$ 15,00 / \mathrm{kg}$. Em períodos de férias, quando a demanda aumentava consideravelmente, os valores pagos nas bases pesqueiras atingiam cerca do dobro ( $R \$ 1,50$ a $R \$ 2,00 /$ corda).

Como já previamente informado, a técnica do "braceamento", combinada ao "gancho", é a mais utilizada pelos tiradores, sendo também a mais adotada pelos caranguejeiros da RESEX Maracanã. Isso ocorre por a considerarem menos prejudicial ao ecossistema e aos indivíduos capturados quando comparadas às outras técnicas de extração existentes ("redinha", "laço" ou "tapagem"). Mencionam, ainda, que esta técnica é 
mais apropriada à captura dos caranguejos em galerias mais profundas, o que tem ocorrido cada vez com mais frequência, tornando a captura somente pelo braço uma tarefa mais difícil. Este aspecto é corroborado pelo resultado de Silva, Melo e Paiva (2008) em pesquisa no município de Quatipuru (PA) e por Oliveira e Maneschy (2014) em Bragança (PA), onde a captura do caranguejo-uçá ocorre por "braceamento" e "gancho", se contrapondo em partes ao de Mourão, Pinheiro e Lucena (2007), no município de Vigia (PA), onde o "gancho" é consorciado ao "laço" para a captura do caranguejo. No sudeste brasileiro, por outro lado, Jablonski et al (2010) descreveram o uso predominante da "redinha", em manguezais da baía de Guanabara (RJ), embora seja um petrecho proibido pela portaria IBAMA n ${ }^{\circ} 52$, de 30 de setembro de 2003 (BRASIL, 2003), apesar das formas mais tradicionais e artesanais de captura, como o "braceamento" e "tapamento" (obstrução das galerias com sedimento do manguezal para forçar o posicionamento do caranguejo próximo à saída); e de outros controversos, como a "cavadeira" (usada para cavar e cortar as raízes do manguezal que atravessam as galerias - vide Pinheiro e Fiscarelli, 2001). Passos e Benedito (2005) destacaram o mesmo para a exploração comercial de U. cordatus em Gargaú (RJ), com o uso predominante e frequente da "redinha" durante todo ano, fato também ocorrente em alguns locais da região nordeste, como no estuário do rio Mamanguape (PB) (Nascimento; Mourão; Alves, 2011).

Conforme Alves e Nishida (2003) e Nascimento et al (2012) o uso da "redinha" indica uma evidente ruptura dos padrões tradicionais de captura da espécie, pois exige um menor esforço físico por parte do catador do que o exigido pela técnica do "braceamento" ou "tapamento". A introdução desta nova tecnologia traz implicações para a conservação, sendo considerada predatória e legalmente proibida, embora seja amplamente utilizada em várias áreas de manguezais por todo o Brasil. Para Jankowsky, Pires e
Nordi (2006) o uso indiscriminado da redinha, aliado ao aumento do número de catadores, maximiza a pressão de coleta, além de promover redução do tamanho médio do caranguejo-uçá. Ainda segundo este autor, esta redução leva a uma prevalência de caranguejos adultos com menor tamanho médio, promovendo alterações expressivas à estrutura populacional e o comprometimento dos elos manguezal-caranguejo e caranguejo-homem. Nascimento et al (2012) relatam como impactos ambientais do uso da "redinha" captura menos seletivas e alta produtividade, a poluição dos manguezais, morte de caranguejos capturados em armadilhas, corte das raízes de Rhizophora mangle e perda de micro-habitat resultante de galerias destruídas e poluídas. Oliveira e Maneschy (2014) destacam que o conhecimento dos tiradores sobre o ambiente em que atuam, incluindo os ciclos biológicos do caranguejo, as fases lunares e as marés influenciam na organização e nas técnicas de captura desse recurso.

O presente estudo foi realizado em uma unidade de conservação (UC) de uso sustentável, implicando no predomínio de métodos extrativos mais tradicionais, já que o manejo nessas unidades sempre devem se pautar no desenvolvimento sustentável local. Tal fato é corroborado pela abundância dos estoques naturais dessa espécie no local, não necessitando, ainda, a introdução de novas tecnologias de pesca para a manutenção ou elevação dos rendimentos de pesca. Isso pode ser verificado em uma análise da CPUE (captura por unidade de esforço) local, que é muito similar em diferentes áreas de manguezal do estado do Pará, a saber: 80-250 caranguejos/homem/ dia (média de 131,8 homem/dia), pelos catadores de Camará, no Município de Marapanim (Mello et al 2006); 60-250 caranguejos/dia (média de 102,7 caranguejos/ homem/dia) em Guarajubal, no mesmo município (Mello et al 2006); e uma média de 167,6 caranguejos/ homem/dia para o Município de Quatipuru (Silva; Melo; Paiva, 2008). Apesar disso, alguns autores têm apontado diferenças sazonais (e mesmo anuais) do volume de 
captura e produtividade do caranguejo-uçá para alguns estuários, como o do rio Caeté (PA) (Glaser; Diele, 2004), principalmente em função da pluviosidade local (161 e 147 caranguejos/catador/dia, durante a estação seca e chuvosa, respectivamente). Tais valores foram similares aos registrados por Diele, Koch e Saint-Paul (2005), para o Furo Grande (PA), com CPUE de 150 caranguejos/ homem/dia, que segundo Araújo (2006) também podem variar com a distância do mar na Península Bragantina (189 a 140 caranguejos/catador/dia para áreas mais externas e internas, respectivamente). Importante ressaltar que os resultados de CPUE obtidos no presente estudo foram relativamente superiores aos do intervalo da amostra (20 a 400), embora em termos médios (92) seja inferior ao dos estudos anteriormente citados. Tal questão pode ser explicada pelas características ambientais distintas dessas últimas áreas de manguezal, dos diferentes métodos de captura, como também do método adotado na pesquisa.

Outro fato constatado na pesquisa é que 84,49\% dos tiradores profissionais entrevistados comercializaram a carne extraída do caranguejo ("massa"). Nascimento (2006) verificou o mesmo no município de Maracanã, salientando que tal demanda estimula um maior esforço sobre os estoques, bem como ações predadoras. Isso foi revelado nas entrevistas informais, onde foi apontado que alguns ignoram a tradicional proteção às fêmeas, o que não é identificado, pois o caranguejo é trazido já esquartejado. A ausência de controle sobre o sexo do indivíduo capturado também se reflete sobre o tamanho dos animais capturados, trazendo efeitos de sobrepesca aos estoques. Uma confirmação disso possibilitará redução ao rendimento da pescaria do caranguejo na RESEX Maracanã, obrigando os caranguejeiros a buscarem áreas de pesca cada vez mais distantes, podendo inviabilizar a pescaria. Segundo informações obtidas através de relatos dos "tiradores" nas entrevistas informais, o fato acima citado já vem ocorrendo, pois, crustáceos de maior porte estão sendo encontrados em regiões cada vez mais distantes, favorecendo aqueles proprietários de embarcações, que conseguem as melhores produções e, consequentemente, maiores rendas.

O ininterrupto crescimento do esforço de pesca sobre os caranguejos na RESEX Maracanã é preocupante, pois embora possa ser evidência de seu elevado potencial produtivo, também pode constituir produção oriunda de novas áreas de pesca, até mesmo fora de seus limites, mas ali desembarcada, para manutenção da renda e sustento dessas comunidades de pesca tradicionais.

\section{CONSIDERAÇÕES FINAIS}

A captura de caranguejo foi bem representativa no município de Maracanã, com cerca de 20\% dos 5.000 usuários da RESEX Maracanã trabalhando na captura do caranguejo, atividade executada predominantemente pelos adultos do sexo masculino. Os profissionais não souberam informar a rentabilidade dessa atividade extrativa apesar do crescente esforço pesqueiro, que foi de 68,9\% em 13 anos (1995 a 2007). Em resposta a demanda do produto houve incremento da intensidade da frequência de captura deste recurso (média de 4,3 dias/semana) e da CPUE (média de 92 caranguejos/homem/dia) sobre os estoques de caranguejo da RESEX Maracanã e seu entorno.

\section{REFERÊNCIAS BIBLIOGRÁFICAS}

ALVES, Rômulo Romeu Nóbrega; NISHIDA, Alberto Kioharu. Aspectos socioeconômicos e percepção ambiental dos catadores de caranguejo-uçá Ucides cordatus cordatus (L. 1763) (Decapoda, Brachyura) do estuário do rio Mamanguape, Nordeste do Brasil. Interciência, Caracas, v. 28, n. 1, p. 36-43, jan. 2003.

ARAÚJO, Ana Rosa da Rocha. Fishery statistics and commercialization of the mangrove crab, Ucides cordatus (L.), in Bragança-PA - Brazil. 2006. 192 f. Tese (Doctorate of Natural Sciences)-University of Bremen, Bremen, 2006.

ASSAD, Luís Tadeu; TROMBETA, Thiago Dias; DEPASSIER, Jorge; ROSA, Albert Bartolomeu de Sousa; GOTFRIT, Carlos Wurmann. Industrialização do caranguejo-uçá no delta do Parnaíba. Brasília: CODEVASF, 2012.

BARBOSA, Andréa Geisa Pereira; MIRANDA, Indiana Katrine Arruda; CAVALCANTE-FILHO, Wagner Gondim; SILVA, Débora Rodrigues Pinto. Aimportância do turismo na vida dos caranguejeiros no município de Parnaíba-PI. In: , 2., 2008, Fortaleza. Anais... Fortaleza: 2008. p. 1-8.

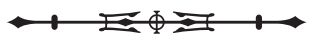


BORCEM, Elielma Ribeiro; FURTADO-JÚNIOR, Ivan; ALMEIDA, Inailde Corrêa; PALHETA, Marllen Karine Silva; PINTO, Ivanilde Albernás. A atividade pesqueira no município de Marapanim-Pará, Brasil. Revista Ciências Agrárias, Belém, v. 54, n. 3, p. 189-201, set./dez. 2011.

BRASIL. Decreto de 13 de dezembro de 2002. Cria a Reserva Extrativista Maracanã, no município de Maracanã, no estado do Pará, e dá outras providências. Diário Oficial da União, Brasília, n. 242, 16 dez. 2002. Seção 1, p. 8-9.

BRASIL. Portaria IBAMA de 30 de setembro de 2003. Dispõe da avaliação e ordenamento da pesca do caranguejo-uçá (Ucides cordatus) das regiões Sudeste e Sul do Brasil. Diário Oficial da União, Brasília, n. 191, 2 out. 2003. Seção 1, p. 123-124.

BRASIL. Decreto de 10 de outubro de 2014. Cria a Reserva Extrativista Marinha Mocapajuba, localizada no município de São Caetano de Odivelas, estado do Pará. Diário Oficial da União, Brasília, n. 197, 13 out. 2014a. Seção 1, p. 2-3.

BRASIL. Decreto de 10 de outubro de 2014. Cria a Reserva Extrativista Marinha Mestre Lucindo, localizada no município de Marapanim, estado do Pará. Diário Oficial da União, Brasília, DF, n. 197, 13 out. 2014b. Seção 1, p. 3-4.

BRASIL. Decreto de 10 de outubro de 2014. Cria a Reserva Extrativista Marinha Cuinarana, localizada no município de Magalhães Barata, estado do Pará. Diário Oficial da União, Brasília, DF, n. 197, 13 out. 2014c. Seção 1, p. 4-6.

BRASIL. Decreto de 10 de outubro de 2014. Amplia a Reserva Extrativista Marinha Araí-Peroba, localizada no município de Augusto Corrêa, estado do Pará. Diário Oficial da União, Brasília, DF, n. 197, 13 out. 2014d. Seção 1, p. 6-7.

CARDOSO, Denise Machado. Mulheres catadoras: uma abordagem antropológica sobre a produção de massa de caranguejo - Guarajubal - PA. 2000. 207 f. Dissertação (Mestrado em Antropologia)Universidade Federal do Pará, Belém, 2000.

CAVALCANTE, Adriana do Nascimento; ALMEIDA, Zafira da Silva de; PAZ, Alexsandra Câmara; NAHUM, Victoria Judith Isaac. Análise multidimensional do sistema de produção pesqueira caranguejo-uçá, Ucides cordatus, no município de Araioses, Maranhão - Brasil. Arquivos de Ciências do Mar, Fortaleza, v. 44, n. 3, p. 87-98, set./dez. 2011.

CONSELHO NACIONAL DE SERINGUEIROS. Relatório sócio econômico e cadastro da Reserva Extrativista Chico Mendes. Rio Branco-Acre, Julho de 1992. 54p. Rio Branco, 1992. Disponível em: $<$ http://www.chicomendes.org.br/seringueiros13.php >. Acesso em: 01 jul. 2015.

CORDOVIL, Amanda Ribeiro; BORCEM, Eliema Ribeiro; FURTADO-JUNIOR, Ivan. Aspectos socioeconômicos da pesca do Caranguejo-uçá Ucides cordatus em São João de Pirabas - Pará. Boletim Técnico Cientifico do CEPNOR, Belém, v. 14, n. 1, p: 17-23, jan./dez. 2014.
CÔRTES, Laura Helena de Oliveira; ZAPPES, Camilah Antunes; DI BENEDITTO, Ana Paula Madeira. Extração e cadeia produtiva do caranguejo-uçá no Norte do Rio de Janeiro. Boletim do Instituto de Pesca, São Paulo, v. 40, n. 4, p. 639-656, out./dez. 2014.

DIEGUES, Antônio Carlos Sant'Ana. Repensando e recriando as formas de apropriação comum dos espaços e recursos naturais. In: DIEGUES, Antônio Carlos Sant'Ana e MOREIRA, André de Castro Cotti (Org.). Espaços e recursos naturais de uso comum. São Paulo: NUPAUB-USP, 2001. p. 97-124.

DIELE, Karen; KOCH, Volker; SAINT-PAUL, Ulrich. Population structure, catch composition and CPUE of the artisanally harvested mangrove crab Ucides cordatus (Ocypodidae) in the Caeté estuary, North Brazil: Indications for overfishing. Aquatic Living Resources, Plouzané, v. 18, n. 2, p. 169-178, abr./jun. 2005.

FISCARELLI, Ana Gláucia; PINHEIRO, Marcelo Antônio Amaro. Perfil sócio-econômico e conhecimento etnobiológico do catador de caranguejo-uçá, Ucides cordatus (Linnaeus, 1763), nos manguezais de Iguape (24 $\left.41^{`} \mathrm{~S}\right), \mathrm{SP}$, Brasil. Actualidades Biológicas, Medellín, v. 24, n. 77, p. 129-142, jul./dez. 2002.

FURTADO-JÚNIOR, Ivan; TAVARES, Márcia Cristina da Silva; BRITO, Carla Suzy Freire. Estatísticas das produções de pescado estuarino e marítimo do estado do Pará e políticas pesqueiras. Boletim do Museu Paraense Emílio Goeldi. Ciências Humanas, Belém, v. 1, n. 2, p. 95-111, maio/ago. 2006.

GLASER, Marion; DIELE, Karen. Asymmetric outcomes: assessing central aspects of the biological, economic and social sustainability of a mangrove crab fishery, Ucides cordatus (Ocypodidae), in North Brazil. Ecological Economics, Amsterdam, v. 49, n. 3, p. 361-373, jul. 2004.

INSTITUTO CHICO MENDES DE CONSERVAÇÃO DA BIODIVERSIDADE. Três novas Reservas Extrativistas Marinhas são criadas no Pará. Local: editora, 2014. Disponível em: < http://www. icmbio.gov.br/portal/comunicacao/noticias/5044-tres-novas-reservasextrativistas-marinhas-sao-criadas-no-para.h9tml>. Acesso em: 01 jul. 2015.

IVO, Carlos Tassito Corrêa; DIAS, Antonio Fernandes; BOTELHO, Emanuel Roberto Oliveira; MOTA, Raimundo Ivan; VASCONCELOS, José Airton; VASCONCELOS, Edna Maria Santos. Caracterização das populações de caranguejo-uçá, Ucides cordatus cordatus (Linnaeus, 1763), capturados em estuários do Nordeste do Brasil. Boletim Técnico Cientifico do CEPENE, Tamandaré, v. 8, n. 1, p. 7-43, jan./dez. 2000.

JABLONSKI, Silvio; AZEVEDO, Alexandre de Freitas; MOREIRA, Luiz Henrique Arantes; SILVA, Orjana Carvalho Alcântara. Uma avaliação das capturas do caranguejo-uçá (Ucides cordatus) nos manguezais da baía de Guanabara, Rio de Janeiro, Brasil. Revista da Gestão Costeira Integrada, Rio de Janeiro, v. especial, n. 2, p. 1-8, 2010.

JANKOWSKY, Mayra; PIRES, José Salatiel Rodrigues; NORDI, Nivaldo. Contribuição ao manejo participativo do caranguejo uçá, Ucides cordatus (L., 1763), em Cananéia - SP. Boletim do Instituto de Pesca, São Paulo, v. 32, n. 2, p. 221-228, jul./dez. 2006

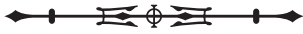


LACERDA, Luiz Drude de. Os manguezais do Brasil. In: VANNUCCI, Marta. (Ed.). Os manguezais e nós: uma síntese de percepções. São Paulo: Editora da Universidade de São Paulo, 2003. p. 193-205.

LINNAEUS, Carolus. Centuria Insectorum, quam, praeside D. D. Carl von Linné, proposuit Boas Johansson, Calmariensis. In: LINNAEUS, Carolus, Amoenitates Academicae; seu dissertationes variae, physicae, medicae, botanice, antehac seorsim editae, nunc collectae et auctae. Uppsala: Sumtu \& Literis Direct. Laurent Salvii, 1763. v. 6, p. 384-415.

MACHADO, Denise. Catadoras de caranguejo e saberes tradicionais na conservação de manguezais da Amazônia brasileira. Revista Estudos Feministas, Florianópolis, v. 15, n. 2, p. 485-490, maio/ago. 2007.

MANESCHY, Maria Cristina. Da casa ao mar: papéis das mulheres na construção da pesca responsável. Proposta, Rio de Janeiro, v. 29, n. 84, p. 82-91, mar./ago. 2000.

MELLO, Clara Ferreira de; BELÚCIO, Lucinice Ferreira; NAKAYAMA, Luiza; SOUZA, Raimundo Aderson Lobão de. Perfil socioeconômico dos tiradores de caranguejo-uçá nos manguezais de Marapanin, Pará - Brasil. Revista Ciências Agrárias, Belém, v. 45, n. 1, p. 223-233, jan./jun. 2006.

MORAES, Sérgio Cardoso de; ALMEIDA, Neila de Jesus Ribeiro. Saberes e sustentabilidade no manguezal da São Caetano de Odivelas-PA. Revista Movendo Ideias, Belém, v. 17, n. 1, p. 1-15, jan./jun. 2012.

MOURÃO, Keila Renata Moreira; PINHEIRO, Ludmila Assunção; LUCENA, Flávia Frédou. Organização social e aspectos técnicos da atividade pesqueira no município de Vigia - PA. Boletim do Laboratório de Hidrobiologia, São Luís, v. 20, n. 1, p. 39-52, jan./dez. 2007.

NASCIMENTO, Douglas Macêdo do; MOURÃO, José da Silva; ALVES, Rômulo Romeu Nóbrega. A substituição das técnicas tradicionais de captura do caranguejo-uçá (Ucides cordatus) pela técnica "redinha" no estuário do rio Mamanguape, Paraíba. Sitientibus série Ciências Biológicas, Feira de Santana, v. 11, n. 2, p. 113-119, jul./dez. 2011.

NASCIMENTO, Douglas Macêdo do; FERREIRA, Emmanoela Nascimento; BEZERRA, Dandara Monalisa Mariz da Silva Quirino; ROCHA, Pollyana Dias; ALVES, Rômulo Romeu da Nóbrega; MOURÃO, José da Silva. Capture techniques' use of Caranguejouçá crabs (Ucides cordatus) in Paraíba state (northeastern Brazil) and its socio-environmental implications. Anais da Academia Brasileira de Ciências, Rio de Janeiro, v. 84 n. 4, p. 1051-1064, set./dez. 2012.

NASCIMENTO, Maria Ivete Herculano do. Tempo de fartura e tempo de famitura no litoral do Pará. Boletim do Museu Paraense Emílio Goeldi. Ciências Humanas, Belém, v. 1, n. 2, p. 23-33, maio/ago. 2006.
NORDI, Nivaldo. Os catadores de caranguejo-uçá (Ucides cordatus) da região de Várzea Nova-PB: uma abordagem ecológica e social. 1992. 107 f. Tese (Doutorado em Ecologia e Recursos Naturais)-Universidade Federal de São Carlos, São Carlos, 1992.

OLIVEIRA, Marcelo do Vale; MANESCHY, Maria Cristina Alves. Territórios e territorialidades no extrativismo de caranguejos em Pontinha de Bacuriteua, Bragança, Pará. Boletim do Museu Paraense Emílio Goeldi. Ciências Humanas, Belém, v. 9, n. 1, p. 129-143, jan./abr. 2014

PASSOS, Cíntia Amim; BENEDITTO, Ana Paula Madeira Di. Captura comercial do caranguejo-uçá, Ucides cordatus (L., 1763), no manguezal de Gargaú, RJ. Biotemas, Florianópolis, v. 18, n. 1, p. 223-231, jan./jun. 2005.

PINHEIRO, Marcelo Antônio Amaro; FISCARELLI, Ana Gláucia. Manual de Apoio à Fiscalização do Caranguejo-uçá (Ucides cordatus). Itajaí: Instituto Brasileiro do Meio Ambiente, 2001.

PROGRAMA DAS NAÇÕES UNIDAS PARA O DESENVOLVIMENTO. Documento do Projeto Conservação e Uso Sustentável Efetivos de Ecossistemas Manguezais no Brasil (PIMS 3280). Roma: PNUD, 2008. Disponível em: $<$ http://www.undp.org/content/dam/undp/documents/projects/ bra/00046839_bra07g32 - 3280 fsp brazil mangroves prodoc final - portugues.doc. >. Acesso em: 20 jun. 2015.

SANTOS, Jeyza Lobato dos. A reserva extrativista como alternativa para a sustentabilidade local: $\bigcirc$ caso da Resex Marinha Maracanã - Pará. Mudanças ambientais globais. ANPPAS. Brasília: Associação Nacional de Pós-Graduação e Pesquisa em Ambiente e Sociedade, 2008. 1-14 p.

SILVA, Mauro Marcio Tavares da; MELO, Nuno Filipe Alves Correia de; PAIVA, Rosildo Santos. Aspectos bioecológicos da pesca comercial do caranguejo-uçá (Ucides cordatus, Linaeus, 1763) em Quatipuru-PA. In: SEMINÁRIO INTERNACIONAL: AMAZÔNIA E IFRONTEIRAS DO CONHECIMENTO, 9-11 dez. 2008, Belém. Anais... Belém: NAEA, UFPA, 2008. p. 1-13.

SOUZA-FILHO, Pedro Walfir Martins. Costa de manguezais de macromaré da Amazônia: cenários morfológicos, mapeamento e quantificação de áreas usando dados de sensores remotos. Revista Brasileira de Geofísica, Rio de Janeiro, v. 23, n. 4, p. 427-435, out./dez. 2005.

SPALDING, Mark; KAINUMA, Mami; COLLINS, Lorna. World Atlas of Mangroves. London: ITTO, 2010.

TERCEIRO, Abraão Martins; SANTOS, Juan Jethro Silva; CORREIA, Maria Marlúcia Ferreira. Caracterização da sociedade, economia e meio ambiente costeiro atuante à exploração dos manguezais no estado do Maranhão. Revista de Administração e Negócios da Amazônia, Porto Velho, v. 5, n. 3, p. 94-111, set./dez. 2013.

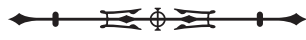


VASCONCELOS, Jussiara Lopes de Almeida. Biologia do caranguejo-uçá e perfis sócio-econômico e etnobiológico dos coletores em duas áreas de manguezais em Ilhéus-BA. 2008. 103 f. Dissertação (Mestrado em Desenvolvimento Regional e Meio Ambiente)-Universidade Estadual de Santa Cruz, Ilhéus, 2008.

VEGAS-VÉLEZ, Manuel. El ecosistema de manglares. Comunicaciones de la Sociedad Malacológica del Uruguay, Montevideo, v. 4, n. 34, p. 347-358, set./dez. 1978.
VIEIRA, Norma; SIQUEIRA, Deis Elucy; EVER, Marcella; GOMES, Maria. Divisão sexual do trabalho e relações de gênero em contexto estuarino-costeiro Amazônico. Amazônica - Revista de Antropologia, Belém, v. 5, n. 3, p. 806-835, set./dez. 2013. 